natural regeneration of forests; and the Agricultural Physicochemical Centre, 3,960,000 francs for work on an improved mothod for the chemical determination of the nutritive elements in soil and the interpretation of the analytical results.

Grants of 3,155,000 francs and 2,670,000 francs went to the Scientific and Technical Research Centre of the Explosives Industry and the Centre for Research on Plant Hormones, respectively ; 2,630,000 francs to the Centre for Research on Parasite Diseases of Domestic Animals ; 2,400,000 franes to the National Committee for the Study of Fruit Cultivation for the equipment of two large conditioning chambers; 2,365,000 francs to the Centre for the Study of the Forest Soils of Ardenne and of Gaume for research on types of forest humus, and 2,240,000 francs to the Centre for Research on Diseases of Ornamental Plants. The Committee for the Study of Agriculture received a grant of 1,975,000 francs; the Plant Physiology Laboratory of the
Gorsem Research Centre, $1,890,000$ francs to extend its researches on the maturation of fruits and their conservation and studies on photosynthesis and on the influence of insecticides and fungicides on the physiology of the vegetables on which they are used; the Centre for Phytopharmaceutical Research, $1,836,000$ francs for research on the utilization of phytopharmaceutical products; and the Committee for the Study of the Solid State, 1,650,000 francs for research on the production of durable magnetic inaterials.

Among other grants are $1,610,000$ francs to the Pedological Service of Belgium, 1,412,000 francs to the Technical and Scientific Centre of the Wood Utiliza. tion Industry, 1,410,000 franes to the Committee for Sitrawberry Research, 1,350,000 francs to the Comrnittee for the Study of Creep of Metals, 1,230,000 francs to the Belgian Centre for the Study of Corrosion "Cebelcor" and $1,080,000$ francs to the Committee for the Scientific Study of Lactation.

\title{
MYOCARDIAL TISSUE CHANGES ASSOCIATED WITH RIGOR MORTIS
}

NITIAL tissue changes associated with rigor mortis do not appear simultaneously throughout the myocardium, their onset being earlier in some areas than in others; such changes result from biochemical modifications occurring after death in myocardial fibres, that is, post-mortem dephosphoryl. ation of adenosine triphosphate and disappearance of creatine phosphate. The evidence from an investi. gation by Piero Gallo, of the Tumour Control Research Centre, Rome, indicates that the adenosine triphosphate and creatine phosphate content in the areas first involved by rigor mortis is significantly smaller than that found to be present in other tissue areas (Cardiologia 37 Supp. 1; 1960). Since adenosine triphosphate and creatine phosphate represent the last link in the long chain of reactions involved in the production of chemical energy, the results enable the rate of this metabolic stage in different tissue areas to be evaluated quantitatively.

Far from being uniform throughout, the rate of energy production appears to be lower in areas where microscopic signs of rigor mortis begin, because these areas have the lowest content of adenosine triphosphate and creatine phosphate; the areas first involved by rigor mortis are segments averaging $20 \mu$ in length of cardiac muscle fibres, the whole width of which is affected.

The non-uniform distribution of adenosine triphosphate and creatine phosphate in the myocardium has been compared with the results of investigations concerning $(a)$ the distribution of interfibrillar cytochondria, which is remarkably uniform; and $(b)$ the diffusion speed of oxygen and energetic materials from the capillaries to the fibres, which varies in tissue areas.

These variations chiefly affect the aerobic phase of metabolism as well as the concentration of creatine phosphate and adenosine triphosphate, which is lower in more slowly oxygenated areas.

Analysis of these experimental findings enables the following conclusion to be drawn: the relatively small amount of adenosine triphosphate in some myocardial areas is not dependent on the distribution of cytochondria, but appears to be due to the fact that such areas are supplied with oxygen at a slower rate than the remaining tissue areas. The slow rate of gas exchanges in such areas seems to be responsible for a marked decrease in the yield of oxidative phosphorylation processes, so ensuring the transfer of chemical energy derived from breakdown and oxidation of energetic materials to creatine phosphate and adenosine triphosphate, which retain it and yield it to myocardial fibrils at the time of contraction.

In the rabbit, topical application of $\gamma$-hexane on the skin at a dose-level of $2 \mathrm{mgm}$./kgm. body-weight does not alter the course of myocardial tissue changes associated with rigor mortis, which exhibit a pattern almost identical to that observed in animals not treated with this insecticide.

\section{BOWER-BIRDS}

T HE popular belief that the display of bowerbirds is either indiscriminate or satisfies some conscious æstheticism has been questioned by Prof. A. J. Marshall, of Monash University (Endeavour, 19, No. 76 ; October 1960). He suggests that, remarkable as they are, the bowers and display paraphernalia of bower-birds are no more than an extension of the territorial and display impulses to be found in other birds. Avian display - visual and auditory - is usually associated with confict and the establishment of territorial domination, pair formation, and seasonal gonad development; final synchronization of the sexual processes of the pair occurs when the environment changes seasonally to a state appropriate for successful reproduction. Only then will the female accept the male. All kinds of widely unrelated birds - for example, waders, grouse, manakins and lyrebirds--make simple display-grounds and posture on 
them during their sexual season. These arenas are evidence of convergent evolution.

In bower-birds a simple display came first. The ontogeny of the satin bower-bird's display can be seen in the increasing elaboration of its ritual as the individual gains in maturity and experience. By scattering a few fragments of blue glass under a wild fig tree on which the young were feeding, Marshall was able to stimulate them to fly down, to snatch up the glass, and to display even without a bower. Later the young green males would build a simple platform of a few twigs and display there with the accumulated coloured objects ; generally these would be stolen from neighbouring adult blue males and carried off to their bowers. As the young green birds grow older, they make low-walled avenue bowers, but before they themselves change colour at the age of five or six years to a mature blue-black they are capable of building a bower as elaborate as that of their elders.
Marshall sees the bower as a result of a displaced nesting-drive. The male, which takes no part in nest building, erects a structure on his display arena. The bower-birds have developed this display tendencyknown in various other species--to an extraordinary degree; some species select coloured objects in the image of male rivals and use them violently in a noisy display which attracts the female and deters interlopers. Strong intraspecific competition has been a powerful factor in the evolution of bower-bird display.

Much has been written about the supposed intel. ligence of bower-birds, but there is evidence that they are no more intelligent than other highly developed passerine species. Much, too, has been written of their alleged conscious artistry ; but their choice is essentially mechanical and unvarying. A species that uses greenish-yellow, for example, will never select green. None, so far as is known, ever varies its colour scheme.

\title{
RADAR ECHOES FROM THE AURORA AT I,300 MC.s.
}

\author{
By Dr. E. EASTWOOD, G. A. ISTED and J. D. BELL \\ Marconi's Wireless Telegraph Co., Ltd., Great Baddow, Essex
}

\begin{abstract}
$\mathrm{D}^{\mathrm{T}}$

Radar frequency
Pulse recurrence frequency
Pulse-length
Power
Aerial rotation
Horizontal beam-width
Vertical polar diagram
Polarization
Aerial gain
\end{abstract}
URING the course of radar experiments directed primarily to the study of the movements of 'angels' and various types of cloud forms, we have recorded some very interesting radar echoes from the aurora at a wave-length of $23 \mathrm{~cm}$. The observa tions have been made with a high-power $L$-band radar possessing the following system parameters :

$$
\begin{aligned}
& =1,306 \mathrm{Mc} . / \mathrm{s} . \\
& =100 \mathrm{p.p.s.} \\
& =5 \mathrm{\mu sec} . \\
& =2 \mathrm{MW} . \\
& =4 \mathrm{r.p} . \mathrm{m} . \\
& =0 \cdot 7^{\circ} \text { (between half power points) } \\
& =\text { cosec.2 (lobe maximum at } 1 \cdot 6^{\circ} \text { ) } \\
& =\text { horizontal } \\
& =10,000
\end{aligned}
$$

During the two years of observations with this equipment the following three sets of auroral echo records have been secured:

$$
\begin{array}{cc}
\text { Date } & \text { Duration of radar aurora } \\
\text { July 15, 1959 } & 15.50-17.15 \text { U.T. } \\
\text { April 1, 1960 } & 14.00-17.50 \text { U.T. } \\
\text { October 6.1960 } & 16.50-18.25 \text { U.T. }
\end{array}
$$

The appearance of the radar aurora as seen on the plan position indicator at 17.43 U.T. of October 6 1960, is shown in Fig. 1. This record shows those essential features of the fully developed aurora which have been substantially reproduced on the occasions listed above, namely, the presence of two auroral arcs, the ranges of the extremities of which lie between $600 \mathrm{~km}$. and $1,200 \mathrm{~km}$., the azimuthal position of the arcs and their lateral extent. The rapidly changing form of the aurora is rendered vividly apparent by the method of time-lapse photography whereby photographs of the plan position indicator are taken so that successive scans of the aerial occupy consecutive frames of a ciné film. Projection of such a film through an ordinary ciné projector running at 16 frames per sec. gives a time compression factor of 240 ; this technique permits the movements of the auroral forms to be clearly observed and measured.
The real or apparent motions of the scattering electron clouds within the auroral ares will be discussed elsewhere; but it is of interest to note that there is a marked tendency for the western limb to show a preponderance of 'receding' clouds.

An interesting feature of the observations of July 15, 1959, was that this auroral record followed a series of plan position indicator photographs taken at sunrise (03.59 U.T.) on the morning of July 14 when the disturbed state of the Sun was made manifest by the greatly enhanced solar noise signal received by the radar. These two direct observations, on the one radar equipment, of the solar disturbance and the subsequent aurora set a time-interval between the two events of $36 \mathrm{hr}$.; this figure has to be increased to $36 \frac{1}{2} \mathrm{hr}$. when the time of first onset of the solar disturbance, as observed by S.I.D.s in the eastern hemisphere, is allowed for. (Solar flare, importance $3+, 03.25$ U.T., 14.7.59.) Such a timeinterval would correspond to an average velocity of the particles emitted from the Sun of the order of $1,133 \mathrm{~km} . / \mathrm{sec}$.

Examination of the advices of magnetic data issued by the Eskdalemuir Observatory shows that

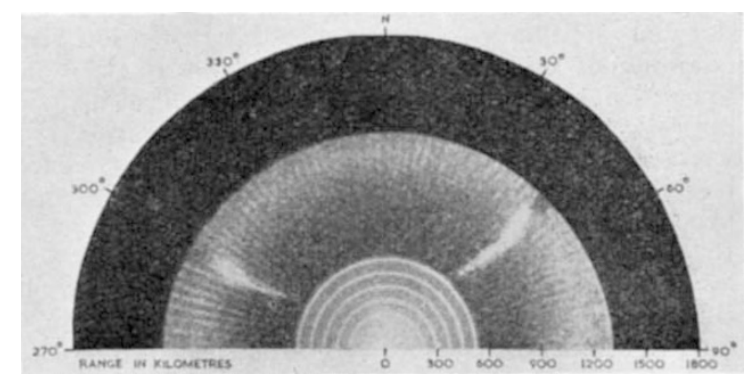

Fig. 1. Radar echoes from the aurora on $1,300 \mathrm{Mc} / \mathrm{s} .(17 \cdot 43 \mathrm{hr}$., October 6, 1960) 